\title{
Strengths and Weaknesses of the Excess Earnings Method for Valuing Backlog
}

\author{
Enrico Gonnella ${ }^{*}$ Lucia Talarico ${ }^{2}$ \\ 1. Department of Economics and Management, University of Pisa, Via C. Ridolfi 10, 56124 - Pisa, Italy \\ 2. Department of Economics and Management, University of Pisa, Via C. Ridolfi 10, 56124 - Pisa, Italy \\ * E-mail of the corresponding author: enrico.gonnella@unipi.it
}

\begin{abstract}
For make-to-order manufacturing firms, a valuable intangibles asset is represented by the backlog, namely a company's sales orders waiting to be filled. Not infrequently, the value of this asset can constitute a significant part of the value of the company.

Valuation experts may be called on to value the order backlog in case of the sale of both one or more contracts and of firms or business units.

A strongly accredited method both in doctrine and in practice for valuing customer-related assets, such as backlog, is the Excess Earnings Method (EEM). However, theoretical contributions on the use of the EEM in the specific estimate of backlog are quite rare.

This paper examines the topic of backlog valuation performed using EEM. After describing the valuation process, a critical analysis of the EEM when applied to such valuation object is carried out, with the aim of grasping its strengths and weaknesses.

We conclude that backlog valuation performed using EEM while on the one hand is characterized by strong economic rationality and enjoys general acceptance in the context of professional business valuation services, on the other it highlights significant elements of uncertainty due to the multiple estimates needed. Moreover, it is an extremely complex and time-consuming process, whose application requires a high level of specialist knowledge and skills on the part of the valuation expert.
\end{abstract}

Keywords: backlog, valuation of backlog, excess earnings method, customer-related assets.

DOI: $10.7176 / \mathrm{RJFA} / 11-22-12$

Publication date: December $31^{\text {st }} 2020$

\section{Introduction}

This paper analyses the critical budget considerations developed by make-to-order manufacturing firms from the point of view of their backlog. In order to understand its relevance, we should first of all recall the distinctive feature of the make-to-order manufacturing firms, i.e. that their work begins upon the receipt of an order from the customer or after being awarded a contract following a bidding process. In this scenario, the products manufactured are defined, in whole or in part, by the customers through their desired technical specifications $\left(\right.$ Note $\left.^{3}\right)$. The products are unique (or almost unique) or, in any case, more or less customized. In other words, they are non-serial products that are produced over a well-defined period of time. They include productions based on unique orders, that are designed and developed after accepting an order, and repeated job orders, characterized by products that have already been designed before receiving the order (e.g. products listed in a catalogue). which are adapted to the customer's requirements and manufactured only after the order. Productions on order are usually quite varied and characterised by low production volumes and a more or less limited standardization. As a rule, they are technically complex and with a high technological content. These productions use very flexible machinery. Sometimes a distinction is made between "large long-term orders", which take several years to be completed, are scarcely standardized and rather complex to be performed from an organizational and managerial point of view, and "small short-term orders", which are completed in a few months (always less than one year) and whose production processes are characterized by a certain degree of standardization.

$\left(\right.$ Note $\left.^{3}\right)$ Contract companies include building and construction companies, shipyards, aerospace companies, manufacturers of large systems, equipment, machine tools, packaging machines, metal and steel manufacturers, mechanical workshops, engineering companies operating in the field of design alone, and many others. 
A typical intangible asset of the companies working on order is the so-called "backlog". The backlog includes products or services that have been contracted but for which the realization has not yet started or has still to be completed.

Specific intangible assets are frequently classified into five categories: marketing-related, customer-related, artistic-related, contract-related, and technology-based intangible assets. This classification is proposed by IVS 210 - Intangible Assets, issued by the International Valuation Standard Council (IVSC, 2020). and by IFRS 3R Business Combinations, issued by the International Accounting Standards Board (IASB). The backlog, as stated by the two abovementioned standards, is included in the second category, that of customer-related intangibles.

The contractual agreement with the customer establishes a reasonable certainty of the amount that will be generated by the orders when they will be complete (Note 4). Ultimately, it is the so-called "contractual-legal criterion" that applies, which excludes the orders for which negotiations are still being held from the list of intangible assets. This criterion is also explicitly referred to in IFRS $3 \mathrm{R}$, where, concerning business combinations, it specifies that: " $A n$ order or production backlog arises from contracts such as purchase or sales orders... [and] ...meets the contractual-legal criterion even if the purchase or sales orders can be cancelled." (IASB, IFRS 3R, IE25). This is something one should firmly keep in mind when completing an estimate.

\section{The valuation of backlog: a literature review}

The valuation of the backlog involves both financial reporting and business valuation. It can therefore be carried out from two different perspectives, although with strong similarities. The valuation of intangible assets at fair value in financial reporting makes the logic and, consequently, the valuation approach and criteria adopted similar to those suggested in the business valuation literature. However, the subject has not been particularly investigated by scholars, who have mostly devoted to customer-related intangible assets generally, which include the order or production backlog (Hitchner, 2011; Zyla, 2013; Trugman, 2012).

Usually, due to the availability of cash flow estimate criteria related to customer-related intangibles and, vice versa, to the difficulty of identifying "similar assets" involved in market transactions, the Income Approach is preferred for the valuation of this category of intangible assets (Reilly and Schweihis, 2016; TAF, 2016; IVSC, 2020). More specifically, the Multi-Period Excess Earnings Method (MPEEM) is recommended, especially when the asset is the primary source of cash flows and income flows for the company (Mard, Hitchner and Hyden, 2010; Hitchner, 2011; Trugman, 2012; Zyla, 2013; Tran and Vrubievskaya, 2016; TAF, 2016).

Among the authors who more than others analyze the Excess Earnings Method we should mention Trugman (2012). who deeply studies the method by focusing on its logical assumptions, also in order to avoid the frequent application errors he finds, such as, for example, the use of historical rather than forward-looking values or the uncritical reference to the percentages indicated in Revenue Ruling 68-609 for the estimate of the capitalization rate (Trugman, 2012). In fact, one should remember that the origins of the method refer to the Appeals and Review Memorandum Number 34 (ARM34) of the US Treasury, dated 1920, later transferred into the Revenue Ruling 68609 (Hitchner, 2011; Trugman, 2012). The author also stigmatizes the frequent abuse of the method, i.e. its use by ignoring its applicability limits, which are clearly specified in the Revenue Ruling. Later on, he explicitly refers to the Fair Value of Customer-related Intangibles with an Excess Earnings Model and observes how this valuation method is the most commonly used for the estimate of customer-related intangibles and technology.

Hitchner (2011) and, similarly, Zyla (2013) investigate the issue of the fair value of intangibles and focus on the MPEEM, of which they confirm the appropriateness for intangibles qualified as "value drivers" (Hitchner, 2011). To make an example, Zyla (2013) refers to customer relationships and technology. Both authors also warn against the risk of duplicating values due to the simultaneous use of the above-mentioned method for more than one intangible asset (Hitchner, 2011; Zyla, 2013). For this purpose, Hitchner reports the warnings contained in the Appraisal Foundation document entitled "The Identification of Contributory Assets and Calculation of Economic Rents" (TAF, 2010). which specify that using the MPEEM simultaneously for "... intangible assets that share the same revenue/cash flow is not best practice and should be avoided." (par. 3.5.05). Even in order to avoid this risk, previously unapplied valuation criteria have been gaining interest in recent years. In this regard, Tran and Vrublevskaya carry out an interesting comparative analysis between the valuation process of the MPEEM and the

(Note ${ }^{4}$ ) In this regard, please note the following: "intangible assets with more readily estimable cash flow streams, such as backlog, may have lower risk than similar intangible assets with less estimable cash flows, such as customer relationships." (IVSC, 2020, IVS 210, par. 90.3.f). 
Distributor Method $\left(\right.$ Note $\left.^{5}\right)$. The dissemination of this latter methodology has been benefited by its description made in the Appraisal Foundation, in the in-depth analysis on the valuation of Customer-Related Assets (TAF, 2016).

In addition, this subject has been, and is still, the target of a special attention by institutions and standard-setters whose mission concerns the regulation of professional practice in the field of business valuation. Indeed, as already pointed out, the documents produced do not dwell specifically on the backlog, but, in most cases, analyse intangible assets as a whole and devote only sporadic references and synthetic digressions to specific categories thereof. For example, in paragraph 20.3 of IVS 210 , which is specifically dedicated to intangible assets, a distinction is made between several categories of intangibles - marketing-related, customer-related, including the backlog; artisticrelated, contract-related, and technology-related intangible assets - but in the following description of the valuation methods and criteria only occasional reference is made to those categories (IVSC, 2020). The customer-related intangible assets and the backlog in particular, are recalled, for example, in the presentation of the Income Approach Methods, but only to say that such methods are the most commonly used for this category of intangibles (IVSC, 2020, IVS 210, par. 60.4) (Note ${ }^{6}$ ). The backlog is also mentioned by the ASC and IAS/IFRS as part of the Customer-Related Intangible Assets category (FASB, ASC 805-20-55-20 up to 28; IASB, IFRS 3R, I323-IE31). For a more in-depth description of the asset and of the most appropriate valuation practices, reference should be made to the Appraisal Foundation document entitled "The Valuation of Customer-Related Assets" (TAF, 2016) which, unlike other sources, offers a systematic and exclusive discussion on this category of intangible assets. The document identifies customer-related assets and sets out the valuation approaches that can be adopted. Then it passes to the analysis of the valuation criteria of each approach, including the MPEEM, which is recommended for primary or even for non-primary assets, when the primary asset can be appropriately valued using another valuation methodology (TAF, 2016, par. 8.1.2.a). The valuation of the backlog acquires a specific importance only in a short paragraph (TAF, 2016, par. 9.2). dedicated to the backlog to highlight the risk of duplicating values when the intangible asset is valuated separately from customers (the customer relationship asset). To avoid this, when the MPEEM is used, the cash flows referred to the two assets must be carefully separated.

It should also be noted that the Appraisal Foundation, with another document (TAF, 2010) already mentioned in this paper, also specifically and broadly reviewed the estimate of an essential parameter of the MPEEM valuation formula, namely Contributory Asset Charges (Note ${ }^{7}$ ). Said document is undoubtedly a benchmark for the abovementioned valuation, even when the methodology is applied for the valuation of customer-related intangible assets, including the backlog.

$\left(\right.$ Note $\left.^{5}\right)$ The Distributor Method is a variant of the Multi-Period Excess Earnings Method. The difference between the first and the second valuation method is essentially related to the estimate of future cash flows, and particularly the expected EBITDA: In the MPEEM, the EBITDA results from business plans, while, in the DM, the EBITDA is estimated by multiplying the revenues of the target company by a percentage of the company's total revenue (EBITDA Margin) taken from a sample of comparable companies. The logic behind the DM, from a value chain perspective, is that companies are made up of various functional areas, each of which generates profits. Considering that commercial companies normally only deal with the distribution function of products, information on their profitability margins can be used as a proxy on which to base the estimate of the residual earnings attributable to customer-related intangibles. Finally, it should be noted that the DM is particularly appropriate for the valuation of customer-related intangible assets when another intangible asset, such as the brand, is considered to be primary or more significant and is valued with the MPEEM. For further information, please read: TAF, 2016, par. 5.3; Tran and Vrublevskaya, 2016; IVSC, 2020, par. 60.33-60.35.

(Note ${ }^{6}$ ) The standard also describes, albeit briefly, the Excess Earnings Method, specifying that it should be applied "... only to a single intangible asset for any given stream of revenue and income (generally the primary or most important intangible asset)." (IVSC, 2020, IVS 210, 60.17).

(Note ${ }^{7}$ ) TAF, 2010, par. 3.6. 


\section{The Excess Earnings Method}

\subsection{Introductory considerations on the method}

The valuation approaches that can be used in the estimate of intangible assets theorized by scholars, as recalled in the valuation principles issued by the various national and international standards-setters (Note 8) and adopted in professional practice, are the same as those applied in business valuation. Their three underlying approaches are: the market approach, the income approach, and the cost approach or asset-based approach (Note 9). In the market approach, the value of an asset is estimated based on the sales prices of comparable items; in the income approach, the estimate mainly refers to expected cash flows, which are converted into a single value through a capitalization or discount process; in the cost approach, an analytical assessment is made, where the value is estimated based on the current cost of replacing or reproducing of an asset, which is the charge that would be incurred at the valuation date to recreate the intangible assets to be estimated. As is well known, each valuation approach includes several valuation methods. Therefore, the valuation of intangible assets requires a selection of the most appropriate approaches and valuation methods.

The backlog generates revenue streams, less uncertain than those generated by relationships with customers as a whole (Note 10). For this very reason, the approach suggested by scholars and which is broadly applied in the valuation of the order backlog is the Income Approach (Tran and Vrublevskaya, 2016). Within this framework, the most used method for estimating customer-related assets, including the backlog, is the Excess Earnings Method (Hitchner, 2011; Trugman, 2012; Tran and Vrublevskaya, 2016).

The Excess Earnings Method (EEM) is based on the assumption that the use of the intangible asset examined allows the company to earn excess earnings, i.e. income flows or cash flows exceeding the expected return of the other tangible and intangible assets that contribute to the generation of net income of the entity. In this method, the intangible asset is valued by discounting or capitalizing the residual excess earnings that it generates. The excess earning attributable to the intangible asset is determined by deducting from the debt-free net income (i.e. EBIT less income taxes or net income before the effect of interest payments to a business's creditors) the Contributory Asset Charges (CACs) of the other tangible and intangible assets, which contributed, together with the asset to be valued, to the generation of the aforesaid net income of the entity. For assets that do not deteriorate in value over time (e.g. land, working capital). CACs consist of a pure investment return in those assets, commonly referred to as return on; while for wasting assets, they consist of both the remuneration of the capital (return on) and the recoupment of the original investment amount (e.g. amortization expenses of intangible assets, brand advertising costs, recruitment and training costs for the assembled workforce). commonly referred to as return of. The excess earnings attributable to the estimated asset are then discounted/capitalized at a rate of return commensurate with its risk.

There are several variants of the EEM. It can be applied by discounting cash flows forecasted for several period (Multi-Period Excess Earnings Method or MPEEM) or for a single period (Single-Period Excess Earnings Method or SPEEM). or again, by capitalizing an average cash flows (Capitalised Excess Earnings Method or Formula Method) (IVSC, 2020, IVS 210, par. 60.8). It is worthwhile noting that the above-mentioned methods are informed by an asset-side logic, where the estimate is based on the debt-free net income.

Passing to the application of the methods described above for the specific valuation of the backlog, it should first be said that a different methodology is used according to the type of orders in the backlog. So, if the MPEEM is used for multi-year contracts to discount multiple cash flows, the SPEEM shall apply for orders to be completed within one accounting period. The Capitalised Excess Earnings Method (CEEM) is not used, as it is normally used to value the goodwill or specific intangible with indefinite-life.

In the application of the EEM (in its MPEEM or SPEEM variants) to the specific valuation of backlog, the valuation process first requires the cash flows from the backlog to be forecasted, net of operating taxes (Note 11). Subsequently, the CACs must be determined and subtracted, to obtain excess earnings of a single period (contracts

$\left(\right.$ Note $\left.^{8}\right)$ There are several standard setters in the field of business valuation. For a broad review, see: Hood, Jr., L.P., Lee T.R., 2011, pp. 135-221.

$\left(\right.$ Note $\left.^{9}\right)$ See, inter alia: IVSC, 2020, IVS 105.

(Note ${ }^{10}$ ) "Customer contracts may represent fairly certain future economic benefits as they usually identify the counterparty, the products and services to be supplied and the expected revenue." (Grant Thornton, 2013).

(Note ${ }^{11}$ ) These are, as is well known, taxes that are determined directly on operating income, which do not take into account the tax deductibility of interest expenses, assuming that the company is financed entirely with equity. 
to be completed within one year) or the excess earnings of several periods (multi-year contracts). to be discounted on the valuation date. Finally, the intrinsic value of the asset so determined will be added to the tax benefit, if the buyer has the right to the deduction of amortization expense of the order backlog, that is the tax amortization benefit (TAB).

Therefore, the basic parameters for the application of the MPEEM or SPEEM methodologies that need to be estimated are:

a) Revenues from backlog.

b) Job Order Costs.

c) Operating taxes.

d) Contributory Asset Charges (CACs) and, on a preliminary basis, the market value and the required rates of return for each contributory asset.

e) The discount rate of excess earnings.

f) The Enterprise Value and the resulting goodwill of the company (Note 12).

g) Weighted Average Return on Assets (WARA) and Weighted Average Cost of Capital (WACC).

h) Tax Amortisation Benefit, if applicable.

The different steps of the valuation process are described below.

\subsection{The forecasting of earnings expected from backlog}

A critical step is the forecasting of the income deriving from the backlog, considered before deducting the remuneration of contributory assets. This calculation is made by estimating the stream of revenue and the costs of the related contracts, as well as by determining operating taxes.

Starting from the various existing contracts, the revenue will then be identified. The determination of the revenue streams expected from the various orders in the backlog is not an easy task, as there are several different situations to be tackled, each characterised by varying degrees of difficulty and uncertainty.

A first differentiation element to be considered is the type of contract signed between the customer and the contractor. These may be Fixed-price contracts or Cost-plus contracts.

In Fixed-price contracts, the contractor undertakes to carry out the work on the basis of a pre-determined contract price or predetermined prices for individual work items.

In Cost-plus contracts, the contract price recognized to the contractor is not pre-determined, but calculated upon completion of the work in either of the two ways described below:

a) By adding to the actual costs incurred both a portion of said costs, to recover overheads and other nonspecifically reimbursable expenses, and the profit margin of the contractor, calculated as a percentage of the costs incurred or pre-determined on the basis of initially estimated costs.

b) By summing up a pre-determined fixed amount to costs actually incurred.

Clearly, the estimate of contract revenues is normally more uncertain in cost-plus pricing contracts than in contracts with pre-determined price.

The amount of contract revenues can also be affected by other variables, namely:

a) Price revisions, which are regulated by specific contractual clauses.

b) Change orders to the original project requested by the customer which are formalized in additional agreements.

c) Other claims for additional consideration made by the contractor for higher costs incurred for reasons related to the customer, for additional work or for change orders not formalized in additional agreements.

d) Incentives - i.e. additional amounts of revenues provided by the contract upon reaching (or exceeding) predefined targets.

Now, the estimate of the revenues expected from the various orders in the backlog does not appear to be an easy task, but rather one that requires special attention. In addition to this, various situations may exist in the different industries where work orders have to be carried out. Undeniably, while the final selling price tends to correspond to the price established in the contract in some works, it may change, even considerably, in others.

One point on which it is important to draw the reader's attention is the possible different status of the orders in the backlog. In fact, there may be two different situations, depending on whether the execution of work or production has already started or if it has not yet started at the valuation date. As regards work started, its value is already

$\left(\right.$ Note $\left.^{12}\right)$ See par. 3.5 below. 
partly included in tangible assets as inventory (Note 13). Therefore, if you value a company and the estimate is made using the asset approach or the economic profit approach, it is necessary to pay attention to possible duplication of value. However, this problem does not exist, for obvious reasons, in the case of orders waiting to be executed at the valuation date. The related contract revenues will therefore be considered for their entire amount in the valuation of the backlog.

Revenue forecasting is the first step in the valuation process. Once revenues deriving from open orders have been forecasted, the subsequent step consists in estimating the costs required for the development of the order, which will have to be subtracted precisely from the aforesaid revenues. The cost forecasting process is characterised by many elements of uncertainty.

First of all, it must be said that the charges to be included in the calculation are both costs that can be directly attributed to the orders in the backlog (direct costs) and costs relating to the production activity in general (indirect costs). By way of example, direct costs include costs of materials used to complete the work, direct labor costs, subcontracting costs, the depreciation of the equipment used, the leasing of machinery and equipment, royalties for patents used for the work, costs for specific guarantees and contract insurances, design costs (if directly related to the contract) and costs for specific contract-related studies. Indirect costs include, for example, design costs (if such costs relate to all production activities and are attributable to several contracts). insurance costs and other construction overheads, commercial and administrative costs (Note 14). With regard to indirect costs, it should be noted that when the activity carried out by the company in the various future periods does not only end up with the execution of the works included in the contract signed at the valuation date, which all together make up the order backlog to be valued, but also includes other orders acquired after that date, then there is a problem with the allocation of indirect costs to either of them. Allocation is never a simple operation. It requires the adoption of systematic and rational criteria, and an adequate management system and an equally adequate cost accounting system. Allocation may be based on expected revenues, if the company has multi-year business plans, or by referring to historical incidence of costs, when no such plans are available. In the former case, the cost driver is the annual revenue. If, for example, 100 is the turnover for the year and 40 is the turnover referred to the orders in the backlog, then indirect costs will be attributed to those orders for a percentage of $40 \%$. In the latter case, the allocation will be based on the average incidence rate of indirect cost on turnover in recent years. Assuming, for example, that the final figures available at year-end show a $15 \%$ average incidence of indirect costs on turnover for the last (n) financial periods, then indirect costs will be estimated to be $15 \%$ of the turnover arising from the orders in the backlog.

Then there are execution costs, whose amount may be affected by variables like those listed below by way of example:

a) Increases (or decreases) in the costs of raw materials or materials used for production and in the cost of direct labour.

b) Difficulties in carrying out work not included in the initial project agreed by the parties.

c) More work required to complete the order not foreseen by the parties.

d) Change orders.

In addition, the forecasting of costs to be included in the valuation process should distinguish, as for revenues, between orders already started and orders waiting to be executed. As regards the former, only the costs still to be incurred for their completion should be taken into account, while in the latter costs must be included for their full amount.

Another aspect worthy of attention is that, typically, the order backlog is a subset of customer relationships. The value of the backlog is related to the goods or services already purchased with a contract at the valuation date, but not yet delivered and invoiced, while the value of customer relationships is also affected by the revenues and profit margins arising from future orders from existing customers. Clearly, if, within the same valuation, the appraiser considers it appropriate to estimate the customer relationship and the production backlogs separately from one other, he will have to pay the utmost attention to the possible duplication of values. In this particular case, the value of the order backlog will have to be excluded from that of customers. The valuation of both assets can be

$\left(\right.$ Note ${ }^{13}$ )In fact, orders already in progress at the valuation date, unlike those not yet started, are partially included in the estimate of "work in progress on order". Indeed, this is the single item in the balance sheet that reflects orders acquired.

(Note ${ }^{14}$ )Marketing costs and study and research costs incurred in acquiring new orders are excluded. See, in this regard, IVSC, 2020, IVS 210, par. 60.11.c.2. 
performed by using the EEM but taking care to exclude the revenues and costs estimated for the order backlog from those related to customer relationship (TAF, 2016, par. 9.2.2).

Once revenues and costs attributable to the orders in the backlog have been estimated, the operating income deriving from the order backlog will be determined by subtracting the latter from the former and, by subtracting operating taxes from that operating income, the Net Operating Profit Less Adjusted Taxes (NOPLAT).

\subsection{The estimate of Contributory Asset Charges and the consequent determination of Excess Earnings}

The determination of excess earnings attributable to the order backlog is obtained by subtracting the charges of the contributory assets (CACs) from the NOPLAT. Therefore, they must be estimated. As noted earlier, contributory assets are the resources that contribute, together with the intangible asset to be valued, to the generation of associated cash outflows (Note 15). In other words, the production process could not be activated without said resources and, in fact, the value of the intangible assets would be nullified. The CACs, as noted earlier, are the costs to be incurred for the use of said assets.

Now, given that contributory assets have changing nature and features depending on intangible asset examined and, on the company concerned, it can be observed that contributory assets include the following items (IVSC, 2020, IVS 210, 60.11.d; TAF, 2010, p. 7):

a) The net working capital (e.g. trade receivables, inventories, trade payables, etc.).

b) Fixed assets (e.g. land, buildings, systems, machinery, equipment, etc.).

c) Other specific intangible assets (e.g. trademarks, patents, technology, software, assembled workforce, etc.).

In the valuation of backlog, some typical contributory assets are the working capital, the fixed assets and the assembled workforce (Note 16). to which we may add other intangible assets (e.g. trademarks, patents, software, technical drawings, etc.). which differ according to the type of production of the company and to the industry in which it operates.

In order to isolate excess earnings that can be logically attributed to the intangible asset under valuation, the appraiser will therefore have to estimate the CACs (Note 17). From a valuation method perspective, the inclusion of the CACs in the valuation of an intangible asset provides an expedient to allocate a portion of the income expected from operations to each of the activities that will support its formation, together with the estimated asset. But how can CACs be determined? The calculation method changes according to the nature of the asset. In the case of contributory assets whose value is not subject to depreciation, CACs represent a pure investment return in those assets (return on) (Note 18); in the case of contributory assets that deteriorate in value over time due to the physical, functional or economic obsolescence, CACs consist of two components: the remuneration of the capital (return on) and the recoupment of the original investment amount (return of). given by the amortizations/depreciation expenses or by the maintenance costs of the contributory asset (Note 19). In any case, the CACs should be determined by taking into account the market value of contributory assets, and not their book value (Trugman, 2012). This is far from negligible since the valuation method in question may require a number of preliminary estimates of other tangible and intangible contributory assets with a more or less significant increase in work from case to case.

$\left(\right.$ Note $\left.{ }^{15}\right)$ "Contributory assets are assets that are used in conjunction with the subject intangible asset in the realisation of prospective cash flows associated with the subject intangible asset. Assets that do not contribute to the prospective cash flows associated with the subject intangible asset are not contributory assets. " (IVSC, 2020, IVS 210, par. 60.7). Similarly: "The distinguishing characteristic of a contributory asset is that it is not the subject income-generating asset itself; rather it is an asset that is required to support the subject income-generating asset." (TAF, 2016, p. 34).

(Note ${ }^{16}$ ) "Assembled workforce, as it is quantifiable, is typically the only element of goodwill for which a CAC should be taken.” (IVSC, 2020, IVS 210, par 60.13).

(Note ${ }^{17}$ )For further insight, please read, inter alia: TAF, 2010.

(Note ${ }^{18}$ ) "The appropriate return on a contributory asset is the investment return a typical participant would require on the asset." (IVSC, 2020, IVS 210, par 60.14).

(Note ${ }^{19}$ ) "The return of a contributory asset is a recovery of the initial investment in the asset." (IVSC, 2020, IVS $210,60.14)$. 
As regards the "return on", which represents the first component of CACs, it should be noted that the normal rates of return to be applied to the market values of contributory assets, to determine their appropriate return, must be estimated - as has been appropriately observed (IVSC, 2020, IVS 210, 60.11.e) - based on the risk associated with the latter. Since the risk profile changes between different asset types, it is clear that normal rates of return will vary according to the different types of contributory assets. Indeed, the risk profile of the investment tends to increase, passing from the net working capital to fixed assets and to specific intangible assets, which is the same that will happen for normal rates of return (see Figure 1) (Note 20).

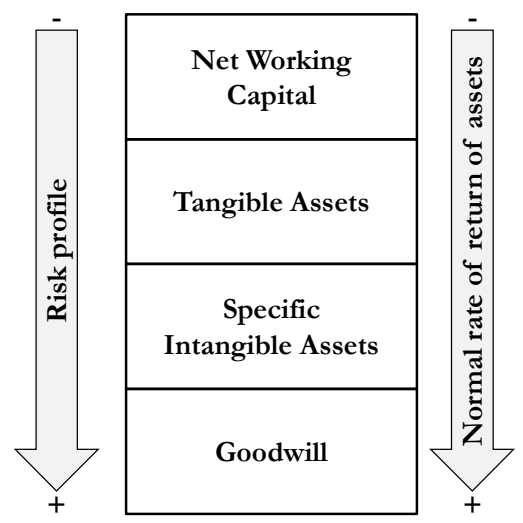

Figure 1. Risk profile and normal rate of return of assets

Turning to the normal rates of return usually applied to the various contributory assets, one can observe the following.

The net working capital is a low-risk asset. In valuation practice, the normal return on this investment is estimated by using as a proxy the short-term market borrowing rate after tax.

Fixed tangible assets are normally characterized by a medium level of risk. In this case, the common practice consists in using as a proxy of normal rate of return the long-term market borrowing rates, i.e. the average mortgage interest rate, or the interest rate in lease or in asset-backed securities (Note 21). considered after tax.

It is not uncommon for contributory assets to include specific intangible assets other than the one being valued, each with a different risk profile. For this reason, the rate of return on intangibles must be determined on a caseby-case basis, taking into account the specific risk profile of each asset. As a rule, the rates adopted exceed those applied to estimate the return on net working capital and fixed tangible assets. This is explained by the high-risk profiles of intangible assets. In fact, the rate of return on these specific intangible assets is not seldom estimated by applying a higher rate than the WACC, even higher than the cost of equity unlevered or than the cost of the equity levered of the company that owns said assets (Note ${ }^{22}$ ). This is also justified by the fact that investments in intangible assets, unlike investments in other categories of assets, are mainly, if not entirely, financed - due to their high-risk profile - by equity (TAF, 2010, par. 4.2). The chosen rates will then have to be applied to the economic values of the various intangible assets, and this requires their estimate.

It is worth remembering that, when a company owns multiple intangible assets, it is advisable to valuate intangible assets other than the main one, estimated with the EEM, with alternative criteria (e.g. Relief from Royalty Method,

(Note ${ }^{20}$ ) “... the risk profile of an entity's assets generally increases as you move down the balance sheet and, accordingly, the type of financing available for the assets shifts from debt to equity as the risk profile increases." (TAF, 2010, p. 24).

$\left(\right.$ Note $^{21}$ )Asset-Backed Securities (ABS) are financial instruments issued against securitization transactions, similar to ordinary bonds. In fact, like these, they also pay periodic interests, the amount of which is determined based on fixed or variable rates. However, their material difference from bonds is that the payment of interests and the repayment of the loan are guaranteed by pool of assets, particularly by cash flows from transferred receivables.

(Note ${ }^{22}$ ) "The study shows that for all the identified sectors, the required return on intangible assets is higher than the WACC." (Schauten, Stegink and Graaff, 2010). 
With and Without Method, or Distributor Method) to avoid cross-estimates of CACs and the consequent circularity issues that make valuations more complex and uncertain (Note 23).

A further aspect to be considered is that, since the market value of contributory assets has been preliminarily estimated by using the Income Approach, the return on that asset will be chosen, for consistency, equal to the discount rate adopted in their valuation (Hitchner, 2011).

The return of an asset, defined as the recovery of the investment in that asset, is a second component of the CACs. Unlike the return on, the return of an asset only applies to wasting contributory assets, whose value is reduced over time. Regarding this type of assets, clearly, in the determination of excess earnings, the appraiser will also have to consider the impairment arising from their obsolescence, so as to prepare the conditions for the assets renewal. Obviously, wasting assets include fixed assets such as buildings, systems, machinery, equipment, vehicles, computers, etc. and various kinds of intangible assets, while the net working capital will be excluded (IVSC, 2020, IVS 210, par. 60.15).

A first necessary observation is that the return of, as well as the return on, an asset must be estimated on the current replacement value of the asset rather than on its carrying amount.

In addition, the methods used for the calculation of the return of an asset differ between fixed assets and intangible assets.

As regards contributory assets included in fixed assets, the return of capital charge can be calculated with two different methods (Zyla, 2013).

A first option is to assume the depreciation expenses of the asset as a proxy of the return of the asset considered, calculated on the current market value of the same asset. The value so estimated will be summed up with the return on the asset, to determine the global CACs for the asset concerned. The appraiser will have to be very careful to avoid any possible value duplicates, which may occur if the depreciation expense of the contributory asset has already been included in the calculation of the EBIT. In that case, only the return on the asset should be considered as CAC. A second solution consist in referring to the hypothetical lease payments that the company would have to pay if the assets were leased. In this case, lease payments would include both the return of and the return on the invested capital for the asset considered.

With regard to the contributory assets consisting of intangible assets, here again there are two alternative technical methods for determining the CACs. A first solution is to use assets maintenance costs (e.g. assembled workforce recruitment and training costs and brand advertising costs) as a proxy for the return of the assets. CACs will result from the sum of the return on and return of the assets, the latter being estimated as described. It should be noted, in this respect, that since maintenance costs might have already been included in the calculation of the EBIT, the considerations previously noted about the risk of value duplicates will apply. In a second method, the CACs of contributory intangible assets will be estimated through the assumed royalties that should be paid for their use. In other words, the assumption is that, if the asset were licensed by a third party, the company would have to pay a periodic royalty for its use. The royalty, in this case too, would simultaneously express the return on and the return of the asset considered (Zyla, 2013).

One final point concerns the estimate of the CACs in the valuation of the order backlog. When the revenues of the orders in the backlog are only a portion of the annual revenues expected by the company, the estimate of the CACs must be made only by considering the portion that can be specifically attributed to the orders in the backlog. Normally this allocation is done by using a specific ratio calculated by dividing the turnover arising from the order backlog by the total turnover.

Including the CACs in the valuation of the order backlog to be estimated, will allow the appraiser to isolate the residual expected cash flows that can be abstractly attributed to that backlog. These cash flows must then be discounted to estimate the market value of the backlog.

(Note ${ }^{23}$ )It goes without saying that, in particular circumstances, such as when there are two primary intangible assets (e.g. customer relations and technology) and it does not seem possible to resort to alternative solutions, the appraiser might be forced to use the Excess Earnings Method simultaneously in the estimate of two assets by adopting the so-called Dual Excess Earnings Method (DEEM). This method can be applied by using four different alternative methods: The Hierarchy method, the Cross-Charge method, the Partial Separation method and the Separation method. For further information, see AICPA, 2013. 


\subsection{The discounting of the excess earnings}

Once excess earnings have been determined, they will have to be discounted to estimate the value of the asset before adding the Tax Amortization Benefit (TAB) (see par. 14.4.6). The value so obtained will be called the "preTAB value" of the order backlog.

The discount rate to be applied to discount the differential income that can be attributed to the order backlog should appropriately take into account the risk profile of the specific asset (IVSC, 2020, IVS 210, par. 60.11.e). Not seldom, appraisers will use the weighted average cost of capital (WACC) or the unlevered cost of equity of the company concerned.

As to the timing of the discounting, in professional practice, intangible assets, including the order backlog, are not rarely valued by applying the mid-year discounting convention rather than the year-end discounting convention (Note 24). In this regard, note that, in the mid-year discounting convention, the discounting factors are calculated for the first year with an exponent of 0.5 rather than 1 , for the second year with an exponent of 1.5 rather than 2 , and so on.

The order backlog is discounted in any case with reference to a limited number of years, while the valuation of customer relations will normally refer to an unlimited horizon.

\subsection{The reconciliation of WARA and WACC}

Once the valuation of the order backlog has bene completed, it is good practice to ascertain the reasonableness of the return on and return of the contributory assets and the rate applied to discount excess earnings.

This verification requires the use of two rates: the Weighted Average Return on Assets (WARA) and the Weighted Average Cost of Capital (WACC). The WARA expresses the average return on the investments made by the company: it is nothing else than the weighted average of the rates of return attributed by the appraiser to the different categories of assets, including the goodwill and the estimated asset. More specifically, the weighting is determined by using as weights the incidence of the market value of the various assets on the Enterprise Value of the company. As is well known, the WACC represents the average cost of a company's various capital sources (Note 25). The basic assumption on which this verification is based is that, referring to the entire business examined, the WARA should correspond to the WACC. See Figure 2.

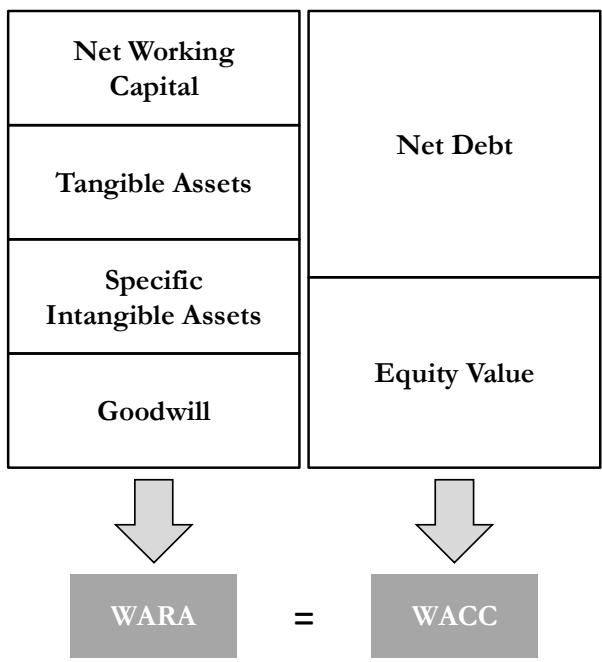

Figure 2. Relationship between WARA and WACC (adapted from Zyla, 2013, p. 286)

(Note ${ }^{24}$ )In the year-end discounting convention, the underlying assumption is that the expected cash flows will be available on the last day of each future period, while in the mid-year discounting convention the underlying assumption is that cash flows will be equally distributed throughout the year.

$\left(\right.$ Note $^{25}$ ) The estimate of the WACC obviously assumes that an adequate long-term financial structure has been analyzed and identified. 
This verification, as one may infer, is performed by comparing the WARA with the WACC and solving the WACC $=$ WARA equation as a function of the rate of return of the goodwill (Note 26). Note that the goodwill is a residual value obtained from the difference between the Enterprise Value and the sum of the estimated market values for the remaining assets, so the rate of return referred to the goodwill is implicit in nature.

The comparison between WACC and WARA allows the appraiser to reconcile the rates of return requested by investors with the rates of return obtained by the various asset classes. Therefore, calculating the WARA contributes to assessing the reasonableness of specific rates of return of assets for the intangible assets identified and the implicit return of the goodwill. This verification is passed when the implicit rate of return of the goodwill is equal to or higher than the rate of return applied to the specific intangible asset considered to be the riskiest for the company in question, starting from the assumption that the goodwill is the most uncertain and risky intangible and the one that requires the highest rate of return. When, on the other hand, the rate of return on the goodwill is lower than one or more of the rates of return applied by the appraiser to specific intangible assets, then the estimates should be reformulated to reconcile the WARA with the WACC. A WARA that is significantly different from the WACC will consequently require a new valuation of both the market values and the rates of return of the different assets. Normally, the process is completed by successive approximations.

In conclusion, the analysis of the WARA is particularly useful in assessing the reasonableness of the values and the specific rates of return estimated for tangible assets and for specific intangible assets, as well as of the value and the implicit rate of return of the goodwill.

\subsection{The estimate of the Tax Amortization Benefit (TAB)}

When an intangible asset can be amortized by the purchaser for tax purposes, the tax deductibility of the amortization may contribute to a significant portion of the market value of the asset, which is precisely reflected by the tax benefit generated by the amortization (IVSC, 2020, IVS 210, par. 110). This additional component of the value of the intangible asset is known as Tax Amortization Benefit (TAB) (Note 27). The TAB is nothing else than the current value of the tax savings resulting from the amortization of intangible assets. It should also be added that, if amortization is deductible from taxes, the TAB will be applied or not applied depending on the approach adopted for the valuation of the intangible asset. It will be considered if the valuation methods used are based on the discounting of expected results or on cost, provided that the values have been expressed net of the relevant taxes, but it should not be included in the estimate if the market approach is adopted, since negotiated prices are likely to have already incorporated the aforesaid tax benefit (fully or pro-quota, depending on the parties' negotiating power) (OIV, PIV, 2015, par. III.5.11). For the valuation of the order backlog with the MPEEM, where cash flows are determined after deducting operating taxes, the condition for the application of the TAB is fulfilled.

The estimate of the tax benefit can be included in the estimate by adopting two alternative methods that may be defined as analytical and synthetic

According to a first methodology, the TAB can be calculated analytically by discounting individual tax benefits (amortization $\mathrm{x}$ tax rate) for a period equaling the tax amortization period. One aspect to be considered here is that the value on which the tax amortization is calculated is the final value of the asset inclusive of the TAB (Post-TAB Value). It is therefore clear that, by adopting the method in question, the calculation of the TAB will require an iterative process. The market value of the intangible asset will be obtained by summing up the TAB so obtained with the Pre-TAB Value.

Then there is a second methodology, by which the market value of the intangible asset can be obtained directly by applying a multiplication factor called "the TAB factor" to the Pre-TAB Value. The TAB factor can be calculated with the following formula:

$$
\text { TAB factor }=\frac{n}{n-\left(a_{n \mid k} \times t\right)}
$$

(Note ${ }^{26}$ ) "In essence, the comparison of the WACC to the WARA is a diagnostic that assists the valuation specialist in reconciling the rates of return required by providers of capital (the WACC) with rates of return earned by various classes of assets (the WARA). Thus, the WARA calculation assists in assessing the reasonableness of the asset-specific returns for identified intangible assets and the implied (or calculated) return on goodwill." (TAF, 2010, p. 27).

$\left(\right.$ Note $^{27}$ ) The TAB obviously applies only if amortization can be deducted from the company's taxes. In fact, the amortization of intangible assets is not always deductible. This depends on the tax legislation of each Country. 
where:

$\mathrm{n}=$ tax amortization period.

$\mathrm{i}=$ discount rate.

$\mathrm{a}_{\mathrm{n} \mid \mathrm{k}}=$ ordinary annuity for " $\mathrm{n}$ " years at the interest rate " $\mathrm{k}$ ".

$\mathrm{t}=$ tax rate.

As to the discount rate to be applied in the two methods described above, two alternative solutions have been identified (IVSC, 2020, IVS 210, par. 110.4):

a) an appropriate discount rate for the company that uses the asset examined, such as the WACC.

b) the same discount rate adopted for the valuation of the asset to be estimated.

The supporters of the first option argue that, since tax amortization abates taxes on the total corporate income, the entire company should be referred to in the estimate of the discount rate. On the other hand, the supporters of the second option argue that the valuation of the asset, also influenced by the TAB, should never refer to streams other than those generated by the specific intangible asset and, for this reason, the discount rate applied in the estimate of the TAB should be the one that has been used in the valuation of the asset (TAF, 2016, par. 5.2.32; Hitchner 2011, p. 936).

The TAB will then be added to the value of the order backlog before the tax benefit, in order to obtain the market value of the intangible asset concerned.

\section{Conclusive remarks}

The estimate of backlog of make-to-order manufacturing firms poses issues regarding the most suitable valuation methodology to be used. The debate may be helped by the consideration that the order backlog is an intangible asset, therefore, one should look for the most suitable valuation methods for this type of assets. The Excess Earnings Method (EEM) is used in particular for the valuation of intangible assets, and it is on this method that this paper has focused.

It was noted that the EEM is a valid method from a conceptual and theoretical perspective. It could be said that it has an intrinsic economic rationality, since the value of the intangibles processed by this methodology, including the order backlog, is linked to the expected income flows that can be abstractly attribute to the intangible and to its specific risk profile. The rational nature of this methodology is obviously a strength.

The EEM is the result of multiple estimates, which are inevitably affected by a more or less significant degree of uncertainty. Some of the main factors of uncertainty that impact specifically the valuation of the order backlog are:

a) The estimate of the revenue expected from the order backlog, the estimate of the costs incurred for the completion of the orders (which is affected by inevitable allocation issues).

b) The estimate of the market values of contributory assets, the estimate of the rates of return of the contributory assets required to value the CACs.

c) The estimate of the share of the CACs to be allocated to the asset being valued.

d) The estimate of the discount rate of the excess earnings allocated to the order backlog.

e) The estimate of the Enterprise Value necessary to identify the value of the goodwill.

f) The estimate of the WARA and WACC - not to mention other less significant estimates.

The uncertainty is somehow a weakness of the methodology at issue.

Finally, it cannot be denied that the EEM is a rather challenging, complex, and time-consuming method, which requires a successive series of estimates. In fact, discounting at an appropriate discount rate the excess earnings ideally related to the intangible asset to be estimated, from which its value is derived, is only the final stage of a valuation process that comprises multiple steps. The use of such a methodology becomes less challenging if it is an integral part of a broader assessment of the company as a whole. In conclusion, the use of the method described requires a rather complex professional judgment, capable of reconciling both the quantitative and qualitative aspects of the valuation problem.

\section{References}

Amaduzzi, A., Gonnella, E., \& Liberatore, G. (a cura di). (2016). I principi di valutazione d'azienda: esperienze nord-americane, europee e internazionali a confronto. Milano: Giuffrè. 
American Institute of Certified Public Accountants (AICPA). (2013). Dual Multi Period Excess Earnings in the Valuation of Intangibles, AICPA, New York [Online] Available: https://m.dhgllp.com/Portals/4/ResourceMedia/publications/dual_excess_earnings_whitepaper.pdf.

Bini, M. (2011). La valutazione degli intangibili. Milano: Egea.

Damodaran, A. (2017). Narrative and Numbers: The Value of Stories in Business. New York: Columbia University Press.

Financial Accounting Standards Board - FASB (2017). ASC 805, Business Combinations.

Giove, G. (2008). Imprese che operano su commessa: un'analisi di costi e redditività, in Amministrazione \& Finanza, vol. 23, n. 1.

Grant Thornton, (2013). Intangible Assets in a Business Combination. Identifying and Valuing Intangibles under IFRS 3. London: Grant Thornton International.

Guatri, G., \& Villani, M. (2010). Valutazione e financial reporting. Milano: Egea.

Guatri, G., \& Villani, M. (2015). Le valutazioni per il Patent Box. Milano: Egea.

Hitchner, James R. (2011). Financial Valuation. Applications and Models. (3rd ed.). Hoboken: Wiley.

International Accounting Standards Board - IASB (2020). IFRS 3R, Business Combinations.

International Valuation Standards Council - IVSC (2020). International Valuation Standards 2017. London: IVSC.

Marasca, S. (ed.) (2015). I principali fattori di incertezza nella valutazione d'azienda. Identificazione, analisi e modalità di gestione. Milano: Giuffrè.

Mard M. J., Hitchner J. R., \& Hyden S. D. (2010). Valuation for Financial Reporting: Fair Value, Business Combinations, Intangible Assets, Goodwill and Impairment Analysis. Hoboken: Wiley.

Marinali, B., \& Onesti, T. (1990). La valutazione del portafoglio lavori in ipotesi di cessione di azienda. Auditing, n. 9 .

Organismo Italiano di Contabilità - OIC (2016). OIC 23, Lavori in corso su ordinazione.

Organismo Italiano di Valutazione - OIV (2015). PIV Principi Italiani di Valutazione 2015. Milano: Egea.

Reilly, R. F., \& Schweihs R. P. (2016). Guide to Intangible Asset Valuation. Hoboken: Wiley.

Saita, M., et al. (2012). Evoluzione dei principi contabili nel contesto internazionale. Milano: FrancoAngeli.

Schauten, M., Stegink, R., \& de Graaff, G. (2010). The discount rate for discounted cash flow valuations of intangible assets. Managerial Finance, vol. 36, 799-811.

The Appraisal Foundation - TAF (2010). The Identification of Contributory Assets and Calculation of Economic Rents. Washington, DC: The Appraisal Foundation.

The Appraisal Foundation - TAF (2016). The Valuation of Customer-Related Assets. Washington, DC: The Appraisal Foundation.

Tran, L. H., \& Vrublevskaya, I. (2016). Methods for Valuing Customer Relationships: Use of the Multi-Period Excess Earnings Method or the Distributor Method?. Forensic Analysis Insights, spring, 70-77.

Trugman, G. R. (2012). Understanding Business Valuation: A Practical Guide to Valuing Small to Medium Sized Businesses. (4th ed.). Hoboken: Wiley.

U.S. Treasury Department, (1920). Appeals and Review Memorandum Number 34 (ARM 34). Washington, DC: U.S. Treasury Department.

Zanda, G., Lacchini, M., \& Onesti, T. (2013). La valutazione delle aziende. (6th ed.). Torino: Giappichelli.

Zanda, G., \& Pucci, S. (1991). La valutazione del portafoglio lavori nella stima del capitale economico dell'azienda. Torino: Giappichelli.

Zyla, M. L. (2013). Fair Value Measurement. (2nd ed.). Hoboken: Wiley. 